\title{
Flying foxes on Choiseul (Solomon Islands) - the need for conservation action
}

\author{
E. Bowen-Jones, D. Abrutat, B. Markham and S. Bowe
}

The Choiseul 1995 project spent 6 months studying the Chiroptera of Choiseul, one of the least disturbed and most poorly known islands in the Solomons. Among the results were: the rediscovery of a member of the Megachiropteran genus Pteralopex, which had been thought possibly extinct; a new record of another endemic pteropodid with a limited distribution; and evidence of a decline in the 'commonest' member of the family in the archipelago. The threats, present and future, to these animals and the forests of the island are discussed. An overview of the status of Pteralopex spp. in the Solomons provides an insight into the need for conservation action in the country as a whole.

\section{Introduction}

Choiseul is a remote island in the Solomons and, compared with other islands in the archipelago, is poorly known in terms of its biogeography. The fauna of the island is very similar to that of neighbouring Bougainville (Figure 1), which, although politically part of Papua New Guinea, is biogeographically part of the North Solomons (Flannery, 1995).

Choiseul is approximately $120 \mathrm{~km}$ long and $40 \mathrm{~km}$ wide. The interior of the island is mountainous, rugged and covered in rain forest, the highest point being Mt Maetambe at $1060 \mathrm{~m}$. Most of the island's 13,000 human inhabitants live within $2 \mathrm{~km}$ of the coast, where their coconut plantations are located and where they were encouraged to relocate by the missionaries who converted the various groups of indigenous people. All land on the island is under customary ownership.

To the authors' knowledge, only two surveys with zoological content had been carried out before the one described here. In 1927 the Whitney South Seas Expedition visited the island collecting specimens and in 1991 an Australian Museum team working in the Solomons collected limited data about the island's fauna. However, according to the oral history of the tribes concerned, the Choiseul 1995 team were the first non-islanders to visit several areas, including Mt Maetambe, an area of cultural significance due to its height. Only several months of working in other areas and talking with the inhabitants to build up trust and thus be granted access to land made this possible.

Choiseul has been rated as being the fifth highest priority area in the world for fruit bat biodiversity and 10 taxa of Megachiroptera have been recorded as present on the island (Mickleburgh et al., 1992; Table 1).

Of particular interest is the Bougainville monkey-faced flying fox Pteralopex anceps (Andersen, 1909), which is confined to Choiseul and Bougainville. This species of Pteralopex is the largest member of a genus characterized by having reduced ears hidden in the fur, and a specialist dentition composed of multicuspate molars and bicuspate canines. Pteralopex anceps is principally known from specimens collected by the Reverend Poncelet in the 1920s, and nothing was known of its natural history. In 1992 Mickleburgh et al. listed this species as Priority Grade 1: Endangered, Limited Distribution, or possibly even extinct. Recent fieldwork had failed to locate a single specimen and the possible reason for the decline of the species was thought to be due in part to the fact that the northern Solomons have the highest density of humans in the archipelago (Mickleburgh et al., 1992). 


\section{E. BOWEN-JONES ET AL.}

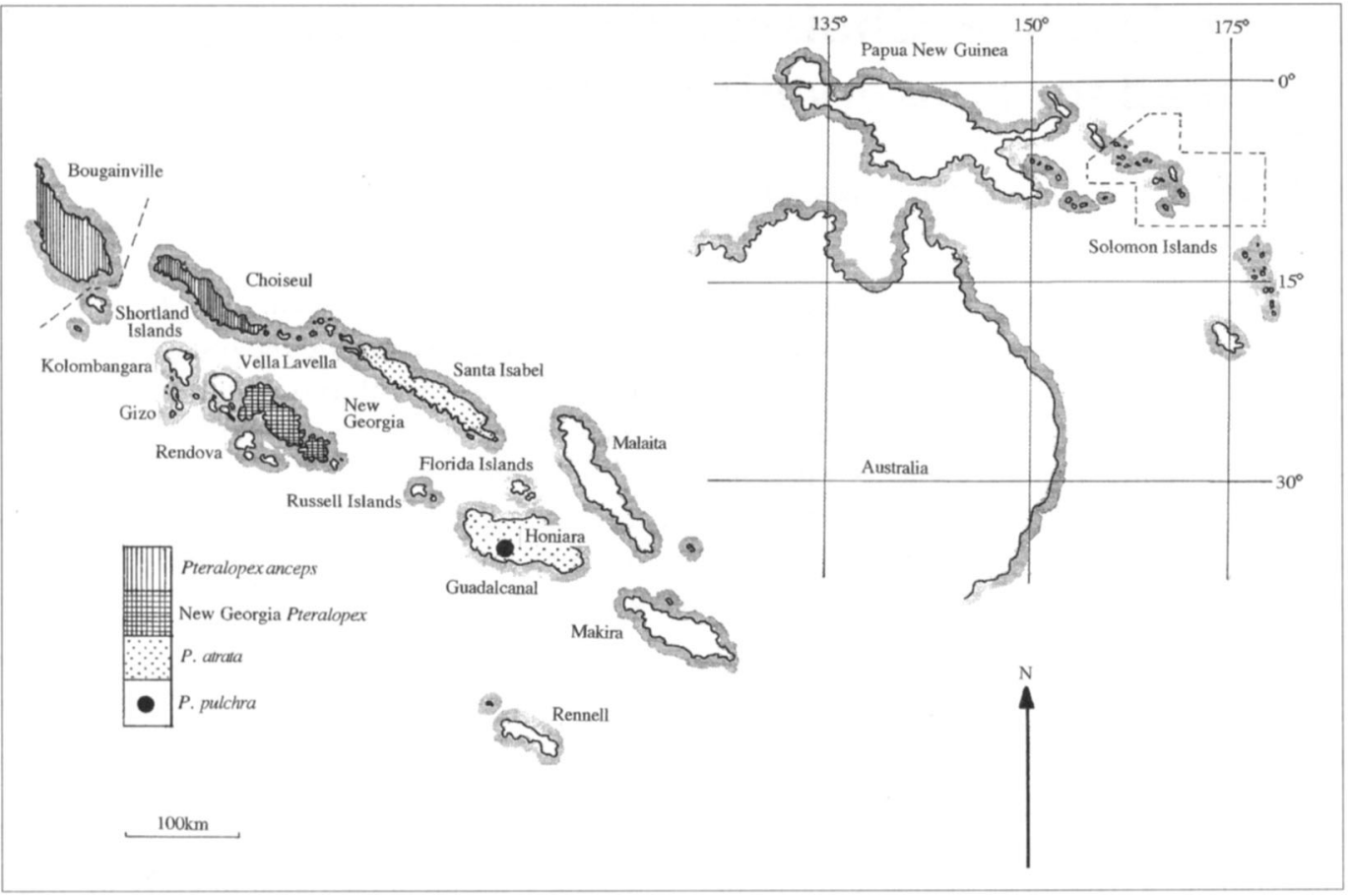

Figure 1. Map of the Solomon Islands, showing the main islands of the archipelago and the recorded distribution of Pteralopex species.

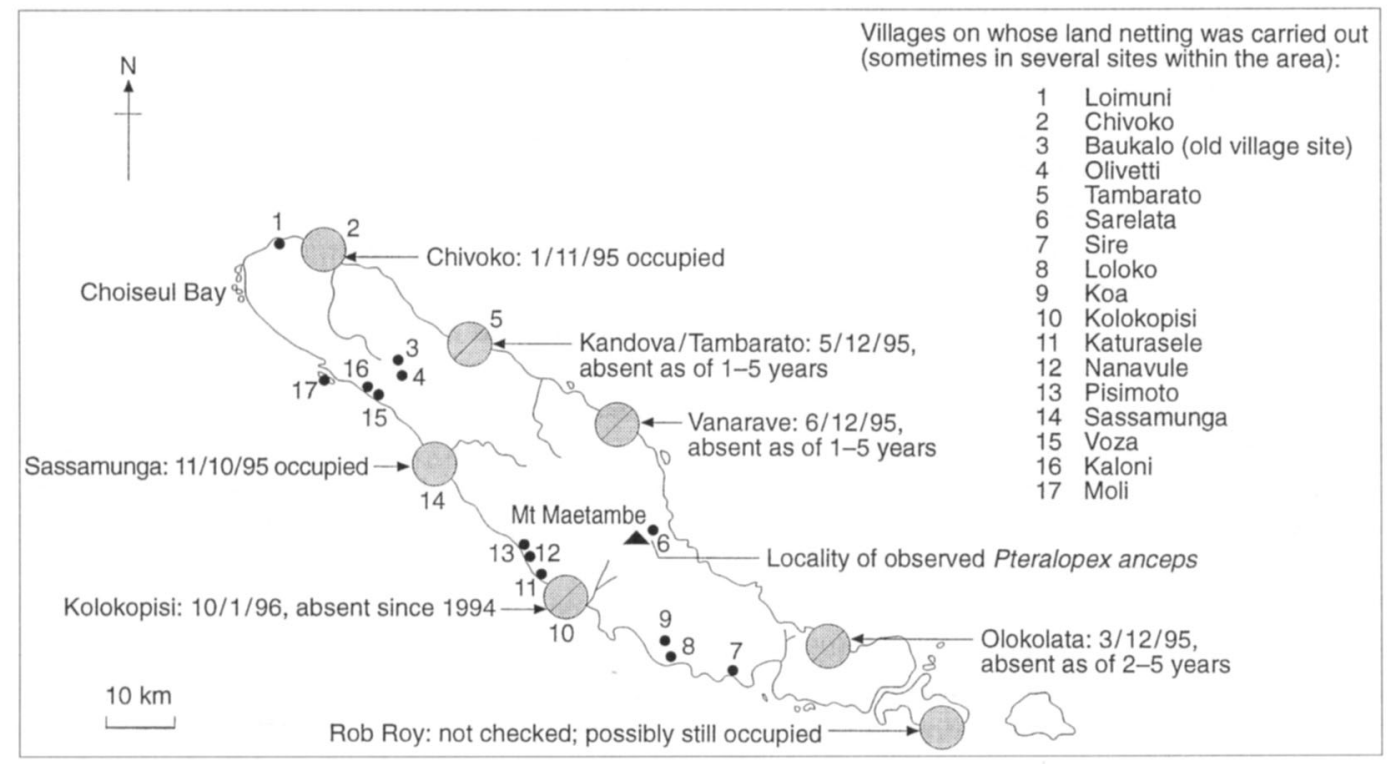

Figure 2. Map of Choiseul, showing past and present Pteropus rayneri grandis roosts and date each was visited by the Choiseul 1995 team. 
Another taxon of particular interest is the largest flying fox on Choiseul, Pteropus rayneri grandis, the largest of the five subspecies of $P$. rayneri in the Solomons. Mickleburgh et al. 1992 classed this subspecies as Priority Grade 11: Not Threatened, but Flannery (1995) described it as Vulnerable because of local population declines caused by disease.

A third species of interest was Pteropus mahaganus, which had not been recorded from Choiseul but had been recorded from neighbouring Santa Isabel and Bougainville, and was suspected as being present on Choiseul (Leary and Aujare, 1994). Mickleburgh et al. (1992) listed it as Priority Grade 3: Vulnerable, Limited Distribution.

The aim of the fieldwork described here was to survey Choiseul to discover whether Pteralopex anceps was extinct, and the size of its population if the species survived (an IUCN/ SSC Chiroptera Specialist Group priority project; Mickleburgh et al., 1992). At the same time the other bat species on the island were to be surveyed.

\section{Methods}

Six months of fieldwork was undertaken between July 1995 and February 1996, a period that overlapped seasons to try and ensure representative records for the year. The team consisted of the authors and two others. The four authors carried out the bulk of the survey work with the aid of local people from the various villages that were used as bases.

Throughout the survey permission was sought from chiefs to work on their landowning group's area. If permission was granted, local people were questioned about bat sightings, caves and roosts in the area. These places were then checked to see if bats were present, what species they were and the topography of the surrounding area to assess the best method of estimating populations. In addition, attempts were made to capture individuals by setting mist nets around fruiting trees and in 'gardens' (areas used for shifting cultivation) as well as in primary forest. Faeces and parasites were also collected for further analysis.

Areas belonging to villages all round the coast of Choiseul were investigated (Figure 2) but it was impossible to visit large tracts inland because the ownership of many areas is contentious.

Additional information was collected at c. 25 village lectures, which were attended by the majority of inhabitants, and during a lengthy discussion after a lecture at the Lauru (original name for Choiseul) Land Conference, where most of the island's chiefs were assembled.

Table 1. Megachiropteran taxa from Choiseul

\begin{tabular}{lclc}
\hline Taxon & Priority grade & Choiseul 1995 records \\
\hline Dobsonia inermis minimus & 8 No Data: Limited Distribution & Recorded \\
Macroglossus minimus microtus & 10 No Data & Recorded \\
Melonycteris aurantius & 8 No Data: Limited Distribution & $\dagger$ \\
Melonycteris woodfordi & 11 Not Threatened & Melonycteris woodfordi \\
& & woodfordi Present \\
Nyctimene major scitulus & 8 No Data: Limited Distribution & Not recorded \\
Nyctimene vizcaccia bougainville & 10 No Data & Recorded \\
Pteralopex anceps & 1 Endangered: Limited Distribution & Recorded \\
Pteropus admiralitatum colonus & 10 No Data & Not recorded \\
Pteropus rayneri grandis & 8 No Data: Limited Distribution & Recorded \\
Rousettus amplexicaudatus brachyotis & 11 Not Threatened & Recorded \\
Pteropus mahaganus & - & New Record
\end{tabular}

*Source: Mickleburgh et al. (1992).

+ Flannery (1993) considers $M$. aurantius to be a subspecies of $M$. woodfordi, with its distribution restricted to the Florida Islands in the Solomons. 
Pteropus rayneri grandis roosts in coconut plantations, primary and secondary forest, either gregariously in large, obvious, noisy aggregations (McKean, 1972) or solitarily (Leary and Aujare, 1994). Estimation of numbers in large roosts was carried out by walking through the roost in a straight line, trying to count the bats before they were disturbed. This often meant estimating the number of bats in a roost 'patch' and multiplying that by the number of patches. The technique is similar to the direct counts of Mutere (1980), judged by Kunz (1988) to be fairly accurate. Additional dispersal counts were used where possible to gauge and improve the accuracy of the direct counts. Thus, a combination of the most appropriate techniques, dependent on the situation, was used to establish greater accuracy (after Mickleburgh et al., 1992). Solitary roosting individuals were observed in various locations but transects through a variety of habitats failed to reveal the presence of individual bats, which were thus taken to be at non-significant numbers.

As a byproduct of the fact that mist nets were a central part of the surveying techniques used and that cave roosts were visited, a list of the Microchiroptera of Choiseul was also compiled.

\section{Results}

Pteralopex anceps (Senga name, Kunjulu)

The vast majority of people on Choiseul were not aware of the existence of Pteralopex anceps, including those familiar with the forest. This is presumably because people use the coastal areas where the species does not seem to occur. Only two men from more than 60 elders interviewed knew the local name for the animal.

On the afternoon of 25 December 1995 the authors observed five individuals of $P$. anceps hanging beneath the branches of a large fig, Ficus sp., approximately $12 \mathrm{~m}$ above the ground. The tree was on a ridge at $850 \mathrm{~m}$ in primary rain forest (Figure 2). Identification of the bats was enabled, with the use of binoculars, by the absence of large protruding ears and black fur on the head and dorsum with the characteristic absence of fur between the wings (Andersen, 1909). The chest was conspicuously white in colour. All five individuals took flight after 5 minutes because of the disturbance and it was impossible to see how far they flew in the dense vegetation. Another individual was seen on 26 December as it flew from a fig that a local helper was climbing in search of bats. It had been roosting in a small hollow between branches. These were the only observations of this species made during the 6 months of fieldwork.

Pteralopex anceps might be confused with the larger island form of Pteropus admiralitatum, which is dark with relatively short ears, and long silver hairs on the ventral side ( $T$. Flannery, pers. comm.) and is known to roost in groups in large forest trees at higher elevation (Flannery, 1995). However, the authors are convinced that the first sighting represented $P$. anceps owing to the size - equal if not larger than $P$. rayneri (the largest member of Pteropus in the region) and the absence of fur between the wings. T. Flannery verified the second sighting of the single $P$. anceps from the photograph taken of this individual.

Pteropus rayneri grandis (Senga name, Kukuvai)

Pteropus rayneri grandis roosts communally and roosts were only found close to the coast despite extensive work inland. Although the interior of Choiseul is rugged, the terrain around the swampy/mangrove areas that $P$. rayneri grandis favours is flat and covered with thick spiny vegetation in deep mud. The roosts may cover $2 \mathrm{sq} \mathrm{km}$.

Occupied and non-occupied roost sites are shown in Figure 2 together with the dates when they were surveyed and last occupied. The majority of sites seemed to have been vacated and only two areas had large colonies resident. This is surprising in view of reports from other sources of the large numbers of colonies per island (Flannery, 1995), and numerous accounts from local people of seeing the sky filled with bats in the past.

Sassamunga and Chivoko roosts, respectively, held 7188 and 5200 bats. The only roost 
site not checked was Rob Roy Island, which was active, according to the land owner. This roost was apparently approximately the same size as Sassamunga and Chivoko. Given a non-significant density of solitary animals, and the sizes of the active colonies, it seems reasonable to add a conservative 5000 animals for Rob Roy giving a maximum of 17,300 , and a minimum of 12,300 (assuming Rob Roy vacant) for the current total Choiseul population of Pteropus rayneri grandis. Using the same cautious average size of 5000 animals per roost and seven past active roosts, there may have been a decline from perhaps at least 35,000 animals in the last 10 years. This confirms that this subspecies is vulnerable.

\section{Pteropus mahaganus (Babatana name, Gama)}

Our survey results filled in the previously disjunct distribution of Sanborn's flying fox Pteropus mahaganus by recording this species from Choiseul for the first time. This species was caught on numerous occasions in many localities on Choiseul and observed at many others. Previously it had only been known from Santa Isabel and Bougainville, on either side of the study island. It is distinguishable in life from the smaller Dobsonia inermis and larger $P$. rayneri grandis by its rapid flight with its faster wing beat. When seen feeding its yellow/brown mantle makes identification easy. The species appears to be fairly common on the island. Despite this, no roost sites were discovered, although local people said that it roosts in tree hollows in primary forest.

Observations showed that, as suspected by Flannery (1995), P. mahaganus feeds on the inflorescences of coconut rather than the fruit. Additional data were gained on its role in the pollination of sago palm on the island, although the degree of exclusivity is unknown. If, as seems likely, this species is an important pollinator of sago palm and coconut, then it is important to local human economies and communities. In this subsistence-orientated region, the copra harvest from coconuts is the predominant source of income, while the sago palm provides the major building material used for village housing.

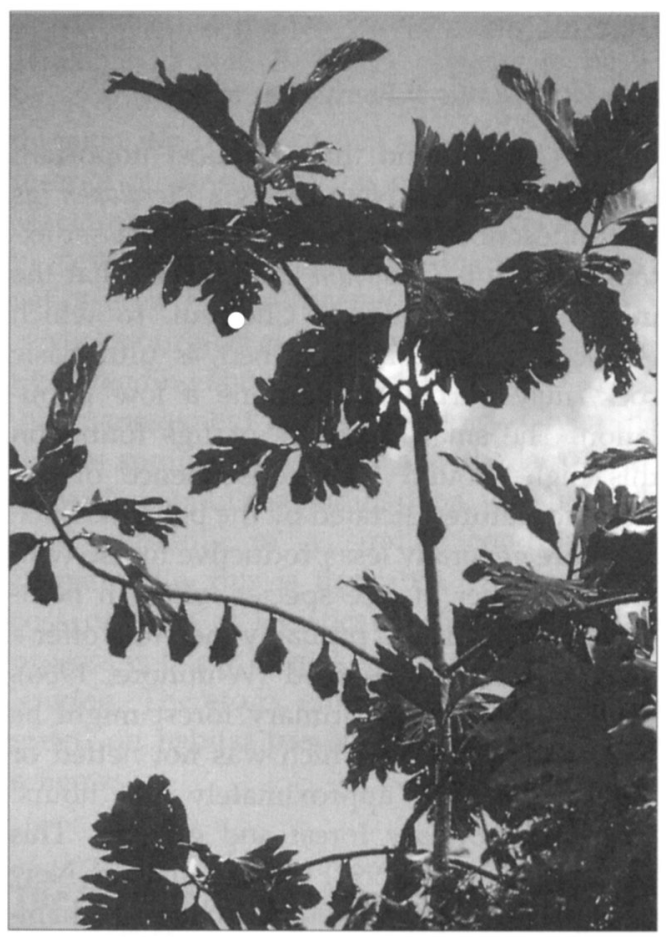

Pteropus rayneri roosting (E. Bowen-Jones).

Pteropus admiralitatum

We did not capture any Pteropus admiralitatum, which had been collected from Reef Island (Choiseul Bay, Figure 2) in the 1920s. As Flannery (1995) noted, this small species is more often found on islets than on large islands. Perhaps this explains its absence from the survey, because the work concentrated on mainland Choiseul.

\section{Microchiroptera}

The results of our survey also included seven new records of Microchiroptera: Emballonura dianae, Emballonura nigrescens, Hipposideros dinops, Miniopterus propitristis, Miniopterus schreibersii and Pipistrellus angulatus. Taxonomy here has been kept to species level because opinions differ about finer divisions; all distributions and nomenclature follow Flannery (1995). The sixth-ever record of the Solomons' flower-nosed bat Anthops ornatus (Hipposideridae) was also made. 


\section{Discussion}

Population status of Pteralopex anceps

Fisher (1992) found that the most important roost trees for the New Georgia Pteralopex (as yet undescribed) were figs, and to a lesser extent ngali nuts Canarium sp. The fact that the inland high ground of Choiseul, to which $P$. anceps now seems confined, is ultra-basic rock, may partially determine a low population. The small numbers of figs found on this high ground is a consequence of the edaphic features dictated by the bedrock. Such areas are generally less productive forest, with a low number of tree species, often in homogenous stands, and probably therefore offer a lower availability of food (Whitmore, 1966). Food availability in primary forest might be crucial to $P$. anceps, which was not netted or observed during approximately 800 hours' work in secondary forest and gardens. This fits with Fisher's (1992) reports that the New Georgia Pteralopex is absent from these habitats; she found that primary forest and old village sites had a higher number of fig trees (roosts) and ngali nut trees (food). Pteralopex anceps probably has a similar diet to the New Georgia Pteralopex, and other species of the genus, which is predominantly based on nuts. This is based on the generic feature of specialist dentition. As a rule the genus is confined to primary forest (Flannery, 1995). Fisher (1992) described how the New Georgia bat seems to associate with a roost site allowing recapture. The reverse may be true of $P$. anceps, where individuals disturbed from the roost had still not returned 2 weeks later.

\section{Absence of Pteropus rayneri grandis from established roosts}

The absence of $P . r$ grandis from past roost sites may have been seasonal, but local people in all of these areas claimed that bats had not been present for 2-5 years. It would seem unlikely that the absence of populations was due to inter-island seasonal migration, because of the reported length of absence and the fact that the roosts containing large existing populations were constantly occupied throughout the study and had been for as long as people could remember.

The reduction of Choiseul $P$. rayneri grandis populations could be due to several possible factors.

1 Disease. Flannery (1990) described P. rayneri grandis populations being wiped out by epidemic disease in Bougainville and Buka (an island off north-west Papua New Guinea) in 1987. He also suggested that, because of its exceptionally high fatality, the disease may have been introduced. In Kolokopisi, Choiseul, the chief described to us how within a week or so in 1994 the large colony 'thousands' strong 'fell down from the trees'.

2 Red ants. Many local people referred to P. $r$. grandis roosting in large numbers in coconut plantations in the past. However, this is not the case now and many people thought this was due to introduction in 1987 of red ants from the Russell Island (central Solomons) strain of coconuts. This occurred throughout the Solomons and would fit with Flannery's description of population decimation in Bougainville in 1987. The ants are known to attack the eyes of cuscus Phalanger orientalis and the irritation and stress this induces may prevent bats roosting. In addition, it is possible that whatever disease is affecting $P$. rayneri, the vector is the introduced red ant. Perhaps a more likely scenario is that another organism was introduced in the same way as the ant and this is the source of the epidemics. 3 Cyclones. According to many people the population of flying foxes on the island has not recovered from Cyclone Ida in 1972. This destroyed large roost trees in several areas and apparently reduced the roost area at Chivoko to one-third the original.

4 Hunting and trapping. Hunting does not seem to be of primary concern on Choiseul where the fruit bat is deemed to be an occasional treat. Leg-hold snares are sometimes used to capture bats, as perceived pest control. However, there was no evidence of widescale, intensive trapping.

Perhaps a combination of these and other events caused the decline in the island's bat population while it was in a state of recovery from the 1972 cyclone. Population recovery 
after such events is slow because of the low reproductive rate of these mammals.

\section{Conservation action}

Recommendations have been made to relevant government and conservation organizations in the Solomons for protection of $P$. rayneri grandis roosts on Choiseul. However, from the evidence of declining populations on Malaita, Bougainville and Buka, north-west Papua New Guinea (Flannery, 1990) it would seem that such measures may be necessary throughout the whole of the Solomons for all subspecies. Community-based education schemes on the ecological importance of bats and the establishment of protected areas would be the most appropriate measures. Research also needs to be carried out to monitor populations of this species over a longer period of time and gauge the degree of threat it is under. Currently, rapid clearance of mangroves and other forests on many islands in the archipelago threaten habitat and wild food resources. With the pressures discussed, plus an increased reliance on gardens as foraging areas leading to more 'pest' control, $P$. rayneri is under imminent threat. Perhaps education, leading to the realization of the true ecological value of fruit bats, would reduce the current use of snares as 'pest' control. At the moment these are often placed indiscriminately, particularly on coconuts, affecting $P$. rayneri and P. mahaganus.

There are a great number of potential pressures capable of reducing the extant population of $P$. anceps as socio-economic factors force villagers to sell customarily owned land for commercial clear felling. Some of Choiseul's forest cover has already been lost and many new licences are in the process of being granted. This destroys feeding and roosting habitat. However, the more desirable selective logging may also reduce available roost trees for Pteralopex and probably Pteropus mahaganus. If $P$. anceps is as sensitive to disturbance as it seems to be, then the only hope for conservation is to preserve large areas of untouched forest. Whether due to natural densities or restriction that human disturbance places on available habitat, $P$. anceps appears to be in low numbers. Thus, logging may now threaten the future of this species. A suitable reserve of forest may be possible in the $\mathrm{Mt}$ Maetambe region, where there is local interest in setting up a community-owned conservation area (Bowen-Jones et al., 1996).

Mickleburgh et al. (1992) suggested that captive breeding should be considered as a possible management tool for $P$. anceps. Given the threats summarized above and the lack of information about the populations, which are almost certainly in a similar condition on Bougainville, this is desirable. However, the cost of such a logistically difficult capture process is likely to make such a scheme challenging. Therefore, effort should be concentrated on habitat preservation and education schemes.

\section{The Solomons: a conservation imperative}

Choiseul has particular relevance in being the least developed of the larger islands in the Solomons. If its forests are clear-felled most of the species found there will survive on Bougainville. Although this island is zoologically almost identical to Choiseul (from what little is known of its fauna) it is politically part of Papua New Guinea. Pteralopex anceps, along with other species such as Poncelet's giant rat Solomys ponceleti, are confined to these two islands of the North Solomons. However, there is no reason to suggest that the more populous Bougainville will not be subject to even more unsustainable development pressures once a solution has been found to the current conflict there, so there can be no complacency. The other islands in the Solomons also have limited-distribution, endemic species on them.

The general situation for Solomons' fauna and flora (low diversity of canopy species but high endemicity; Whitmore, 1966) can be illustrated with reference to the biogeography of the genus Pteralopex. All known species occupy one or two islands at the most (Figure 1). 
All are threatened by current logging practices. For example: the New Georgia Pteralopex is known to have occupied Kolombangara as well, but the clearance of 80 per cent of forest and replacement with plantations has caused its extinction there (Flannery, 1995). Now increasing logging on New Georgia threatens to extirpate the species. Pteralopex atrata on Guadalcanal faces a similar collapse due to the forecast of all forest below $800 \mathrm{~m}$ being lost within the next decade. On this island it seems to be replaced by Pteralopex pulchra above this height, the only record of altitudinal zonation in Solomon mammals (Flannery, 1991). P. pulchra is only known from one specimen.

Although there is a complete absence of ecological information on the role of fruit bats in the ecosystem of these islands, it is possible that, as in other Pacific islands, a third of the canopy tree species rely on flying foxes for pollination or seed dispersal (Cox et al., 1992); and they provide potential economic benefits as pollinators of cash crops. There is urgent need for action.

\section{Further research}

In order to ascertain more about the population of Pteralopex anceps further netting must be carried out in Choiseul's interior with large/owl-mesh mist nets. At the time that this work was carried out on Mt Maetambe only smaller mesh nets were available and several large pteropodids 'bounced' off; one of these was probably $P$. anceps. With the capture of $P$. anceps there should be an effort made to radio-track them in the Maetambe region, which might enable the location of roost sites and therefore estimation of numbers.

Using the same techniques, an easier project would be to work on the more widely distributed, little-known and potentially economically important Pteropus mahaganus. With the setting of mist nets at sufficient height around suitable trees these were relatively easy to catch. If owl-mesh were used, there would be a higher rate of success.

Much of this research will encounter problems with land access. Without long time periods available to carry out this work, logistical, political and equipment factors (because of climate, plus distance and cost of resupply) are likely to conspire against the collection of data.

Environmental education is desperately needed throughout the Solomons, and other species of Megachiroptera and other mammals and birds await urgent investigation. In many cases the time scale for this to be carried out is well inside a decade before all forest will have been lost, and with it undoubtedly many of the endemic species that inhabit these small Pacific islands.

\section{Acknowledgements}

Thanks to Phil Richardson of The Bat Conservation Trust and Gilla Carstairs, who were project members for the first few months. We would like to thank WWF Community Resource Development Fund, Bristol University Expedition Fund, Alumni Foundation, Hosier Fund, British Ecological Society, Royal Geographic Society, Intervet Bursary, Institute of Biology, Gilchrist Trust, Bat Conservation Trust, BP Conservation Expedition Programme 1995 and others for making the necessary funding available. In the Solomons we thank: Glynn Galo and Esau Tuza, at the University of the South Pacific, Honiara Division; Tia Masolo and Moses Biliki, at the Ministry of Forests, Conservation and Education; Audrey Rusa, at the Ministry of Training and Education; Myknee Sirikolo at the Botanical Gardens, Honiara and everyone who allowed us to work on their land and capture animals in Choiseul. Finally we would like to thank the following for their help: Professor Paul Racey, Professor Steven Harris, Simon Mickleburgh and FFI, Dr Gareth Jones, and Dr Tim Flannery.

\section{References}

Andersen, K. 1909. Two new bats from the Solomon Islands. Annals and Magazine of Natural History, London, (8) 3, 266-270.

Bowen-Jones, E., Abrutat D., Markham W. and Bowe, S. 1996. Report of the Bristol University, Choiseul 1995, Survey of Fruit Bats on Choiseul, Solomon Islands. Unpublished. University of Bristol

Cox, P.A., Elmquist T., Pierson E.D. and Rainey W.E. 1992. Flying Foxes as pollinators and seed dispersers in Pacific island ecosystems. In Pacific Island Flying Foxes: Proceeding of an International Conservation Conference (eds D. E. Wilson and G. 
L. Graham), pp. 18-23. US Fish and Wildlife Service Biological Report 90 (23). US Department of the Interior, Fish and Wildlife Service, Washington, DC.

Fisher, D. 1992. Investigation of the Ecology of a New Species of Monkey-faced Bat from the Solomon Islands. Unpublished report, Mammal Section, Australian Museum

Flannery, T.F. 1990. Flying foxes in Melanesia: populations at risk. Bats, 7, 5-7.

Flannery, T.F. 1991. A new species of Pteralopex (Chiroptera: Pteropididae) from montane Guadalcanal, Solomon Islands. Records of the Australian Museum, 43, 123-130.

Flannery, T.F. 1993. Revision of the fruit bats of the genus Melonycteris (Pteropodidae: Mammalia) Records of the Australian Museum, 45, 59-80.

Flannery, T.F. 1995. Mammals of the Southwest Pacific and Moluccan Islands. Australian Museum/Reed Books, Chatswood, NSW.

Kunz, TH. 1988. Ecological and Behavioural Methods for the Study of Bats. Smithsonian Institution Press, Washington, DC.
Leary, T. and Aujare, I. 1994. Review of the Status and Distribution of Pteropus Flying Foxes in Solomon Islands and a Preliminary Assessment of Fruit Crop Damage in Temotu Province. The Nature Conservancy, Honiara Field Office, Solomon Islands.

McKean, J.L. 1972. Notes on some Collections of Bats from Papua New Guinea and Bongainville Island. CSIRO Division. of Wildlife Research Technical Paper No. 26.

Mickleburgh, S.P., Hutson, A.M. and Racey, P.A 1992. Old World Fruit Bats: an Action Plan for their Conservation. IUCN, Gland, Switzerland.

Mutere, F.A. 1980. Eidolon heloum revisited. In Proceedings 5th International Bat Research Conference (eds. D. E. Wilson and A. L. Gardner), pp.145-150. Texas Tech University Press, Lubbock.

Whitmore, T.C. 1966. Guide to the Forests of the British Solomon Islands. Oxford University Press, Oxford.

E. Bowen-Jones, D. Abrutat, B. Markham and S. Bowe, 12 Aldersmead Road, Beckenham, Kent BR3 1NA, UK. 